\title{
The Association Between Health Information Seeking on the Internet and Physician Visits (The Seventh Tromsø Study - Part 4): Population-Based Questionnaire Study
}

Kassaye Yitbarek Yigzaw ${ }^{1}, \mathrm{MSc}, \mathrm{PhD}$; Rolf Wynn ${ }^{2,3}, \mathrm{MD}, \mathrm{PhD}$; Luis Marco-Ruiz ${ }^{1}$, MSc, PhD; Andrius Budrionis ${ }^{1}$, MSc, PhD; Sunday Oluwafemi Oyeyemi ${ }^{4}$, MD, MSc, MPH; Asbjørn Johansen Fagerlund ${ }^{1}$, MSc, PhD; Johan Gustav Bellika ${ }^{1,2}, \mathrm{MSc}, \mathrm{PhD}$

\footnotetext{
${ }^{1}$ Norwegian Centre for E-health Research, University Hospital of North Norway, Troms $\emptyset$, Norway

${ }^{2}$ Department of Clinical Medicine, Faculty of Health Sciences, UiT The Arctic University of Norway, Tromsø, Norway

${ }^{3}$ Division of Mental Health and Addictions, University Hospital of North Norway, Troms $\varnothing$, Norway

${ }^{4}$ Department of Community Medicine, Faculty of Health Sciences, UiT The Arctic University of Norway, Troms $\varnothing$, Norway
}

\section{Corresponding Author:}

Johan Gustav Bellika, MSc, PhD

Department of Clinical Medicine

Faculty of Health Sciences

UiT The Arctic University of Norway

Postboks 6050 Langnes

Tromsø, 9037

Norway

Phone: 4795748049

Email: johan.gustav.bellika@ehealthresearch.no

\begin{abstract}
Background: The internet is being widely used for seeking health information. However, there is no consensus on the association between health information seeking on the internet and the use of health care services.

Objective: We examined the association between health information seeking via the internet and physician visits. In addition, we investigated the association between online health information seeking and the decisions to visit and not to visit a physician.

Methods: We used the cross-sectional electronic health (eHealth) data of 18,197 participants from the seventh survey of the Troms $\varnothing$ Study (Troms $\varnothing 7$ ). The participants were aged $\geq 40$ years and living in Troms $\varnothing$, Norway. We used logistic regression models to examine the association between online health information seeking and physician visits, the decision to visit a physician, and the decision not to visit a physician, with adjustment for the demographic status, socioeconomic status, and health status of the participants.

Results: The use of Web search engines was associated with a physician visit. However, the association was moderated by age, and the OR decreased as age increased. The ORs for the use of Web search engines were 1.99 (95\% CI 1.94-2.02) and 1.07 (95\% CI 1.03-1.12) at ages 40 and 80 years, respectively. The decision to visit a physician was associated with the use of Web search engines (OR 2.95, 95\% CI 2.03-4.46), video search engines (OR 1.43, 95\% CI 1.21-1.70), and health apps (OR 1.26, 95\% CI 1.13-1.42). The association between social media use and the decision to visit a physician was moderated by gender. Women who used social media had 1.42 (95\% CI 1.31-1.55) times higher odds of deciding to visit a physician, whereas the decision to visit a physician was not different between men who used social media and those who did not use social media. Conversely, the decision not to visit a physician was associated with the use of Web search engines (OR 2.78, 95\% CI 1.92-4.18), video search engines (OR 1.27, 95\% CI 1.07-1.51), social media (OR 1.28, 95\% CI 1.10-1.49), and health apps (OR 1.20, 95\% CI 1.07-1.35).

Conclusions: Health information found on the internet was positively associated with both the decision to visit a physician and the decision not to visit a physician. However, the association of health information seeking with the decision to visit a physician was slightly stronger than the association with the decision not to visit a physician. This could imply that the use of eHealth services is associated with a resultant increase in physician visits. In summary, our findings suggest that the internet serves as a supplement to health care services rather than as a replacement.
\end{abstract}


(J Med Internet Res 2020;22(3):e13120) doi: 10.2196/13120

\section{KEYWORDS}

eHealth; internet; health care service; physician visit; Tromsø study; health information seeking; Web search engine; health app; social media; video search engine

\section{Introduction}

Access to the internet is currently widespread. In 2017, around the time the data for this study were collected, the internet coverage of Norwegian households was $97 \%$. Internet access varies between $91 \%$ and $100 \%$ depending on household income. Ninety percent of Norwegians aged between 16 and 79 years use the internet on a daily basis, with similar internet usage between women (87\%) and men (90\%) [1].

Broad access to the internet has triggered a rapid growth in the use of the internet for health-related applications, such as accessing and transferring health information and receiving guidance and support [2-6]. Health information seeking is considered the most common and influential use of the internet [7-11]. Among Norwegian internet users, $62 \%$ used the internet for seeking health information, with a higher proportion of women and younger adults [1], which is consistent with the findings in other countries [8,12-14].

The perceived benefits of online health information seeking include widespread access to health information, convenience (ie, ease and speed), and anonymity [15-19]. These benefits are expected to enable individuals to play an active role in their health care, make better-informed decisions, and possibly improve health outcomes $[18,20,21]$. There are also concerns that the variable quality of online health information combined with limited ability to critically evaluate health information may contribute to negative outcomes, such as unnecessary physician visits, delays in seeking necessary medical care, change in treatments, and seeking alternative treatments that can be harmful [5,16,17,22-26].

In Nordic countries, including Norway, and many other European countries, including the United Kingdom, general practitioners (GPs) represent the basis of publicly funded health services. GPs typically have lists of patients who they are responsible for and see more or less regularly. GPs are expected to diagnose and treat a major proportion of patients and refer only those who need more specialized health services to hospitals for further assessment and treatment (ie, the "gatekeeper" function) [27]. The threshold to seek consultation with a GP may be relatively low, but many GPs are very busy and patients nevertheless have to decide whether their current problem warrants a physician visit [27].

Searching for health information is a complex process influenced by a range of factors. Lambert \& Loiselle [28], in their review, found that the behavior of health information searching is often studied within the context of coping with illness, involvement in medical decision-making, or preventive behavior. Different theoretical frameworks have been applied in research on health information searching [28]. The framework of Miller [29] is one of the most cited frameworks, and a differentiation is made between those who actively engage with information (monitoring) and those who avoid such information (blunting) [30]. Psychological factors, including cognitive and emotional factors [31,32], might be central in the decision-making process for many health information searchers. The process of online health information searching may be powered by not only a need for information about some health- or illness-related topic but also different emotional states, such as anxiety [33], and people with health anxiety are more likely to search for health information [33]. Moreover, how people react to the health information they find online may also vary according to a range of factors, including emotional factors [31,32]. Although finding the required information can result in a positive emotional reaction, it may also result in confusion or increased anxiety [34]. Similarly, the decision to visit a physician or not to visit a physician after finding health information online is a complex process that could be influenced by many different factors, some of which will be examined in this study.

Health information seeking is known to highly influence subsequent health-related behavioral decisions. It has been reported that $46 \%$ of European adults [8] and $48 \%$ of American adults [4] who sought health information via the internet used the information they found to decide whether they needed to see a physician.

Prior studies have found different results regarding the question about whether online health information searching impacts physician visits. Some studies have suggested that searching for online health information can be conducive to increased physician visits. A proposed mechanism underlying this increase in visits is that some individuals may find it difficult to interpret complex and uncertain medical knowledge without the help of health care professionals [35-41]. Therefore, more access to health information via the internet may lead to more uncertainties in understanding health conditions and, consequently, to additional contact with health care professionals. Other studies have found that online health information searching reduces traditional health care service consumption [42,43], and some studies have found no such association [44]. In this study, the objective was to make an accurate assessment of the association between health information seeking and health care service use. We believe that this will be useful for estimating future health care service need in Norway and other countries and for informing future policies related to health care in general and electronic health (eHealth) services in particular.

Studies often capture the outcomes of health information seeking in terms of the decision to visit a physician as a single question that asks if the health information individuals found online led them to decide to visit a physician or not [40]. However, some studies had two questions that capture both outcomes [44], as a single question may not capture both outcomes, given that individuals may make both decisions at different time points in 
a study period. Therefore, a separate question is needed for each of the outcomes.

The seventh survey of the Troms $\emptyset$ Study (Troms $\varnothing 7$ ) included a questionnaire with a wide variety of questions, such as those on the use of eHealth tools, use of health care services, socioeconomic status, and health status. We explored a subset of the data from this questionnaire in a series of four papers. In paper 1, we presented the main findings regarding the characteristics of the participants and their use of eHealth [45]. In paper 2, we studied how the presence of different illnesses influences the use of eHealth [46]. In paper 3, we examined the psychological and emotional outcomes with the use of eHealth [34]. Paper 4 (this paper) aims to study the association between health information seeking using eHealth tools and physician visits. This paper also investigates the associations of online health information seeking with decisions to visit and not to visit a physician.

\section{Methods}

\section{The Study Site}

The participants of the study are inhabitants of Troms $\varnothing$ municipality. Troms $\varnothing$ is a major city in north Norway with a population of around 75,000 inhabitants. The city of Troms $\varnothing$ is located in the sub-Arctic region at 69 degrees North. North Norway is a sparsely populated area with most inhabitants working within the public sector, including health care, education, and administration, and the service sector. Other important employment areas in north Norway are tourism, fishery, agriculture, and some industries.

\section{The Tromsø Study}

The Troms $\varnothing$ Study is a population-based longitudinal health study conducted by UiT The Arctic University of Norway, the National Health Screening Service, and others [47]. Troms $\varnothing 7$ was conducted in 2015-2016 with a focus on inhabitants aged 40 years or above. However, this is the first time the Troms $\varnothing$ Study collected eHealth related information. Therefore, this paper, which is based on eHealth survey data, involves a cross-sectional study. A total of 21,083 individuals $(11,074$ women and 10,009 men) participated in the study, with a response rate of $65 \%$.

\section{Independent Variables}

The variables used in this study were measures of health information seeking via Web search engines (ie, Google), video search engines (ie, YouTube), social media (ie, Facebook), and smartphone or tablet health apps. The variables were constructed from four questions regarding whether a participant had used each of the eHealth tools in the last year. The responses to the questions were "never," "once," "sometimes," and "often." We subsequently dichotomized the responses into "never" and "ever," where "ever" includes once, sometimes, and often.

The other independent variable was a dichotomous measure of whether a participant reported having one or more diseases in the last year. The variable was constructed from questions regarding whether a participant had diseases, such as high blood pressure, heart attack, heart failure, atrial fibrillation, angina, stroke, diabetes, kidney disease, bronchitis, asthma, cancer, rheumatoid arthritis, arthrosis, migraine, psychological problems, and chronic pain. The responses to the questions were "no," "yes," and "yes, previously."

Age, gender, education, household income, occupation, and self-reported health, which are known to influence health information-seeking behaviors, were also controlled for in this study. Age was converted into 10-year intervals, as a small age difference is not associated with a large change in the outcome variables.

\section{Dependent Variables}

In the Troms $\varnothing$ Study, there were three questions examining different aspects of health service use. The first dependent variable was a dichotomous measure of whether the participant had a physician visit in the last year. The variable was constructed from questions that asked whether a person visited a GP, emergency care practitioner, psychologist, or psychiatrist in the last year.

The second dependent variable measures the decision to visit a physician following health information seeking on the internet. The variable was constructed from a question that asked whether a participant decided to visit a physician according to the information found on the internet. The response to the question was "never," "once," "sometimes," or "often." We dichotomized the responses into "never" and "ever," where "ever" includes once, sometimes, and often.

The third dependent variable measures the decision not to visit a physician following health information seeking on the internet. The variable was constructed from a question that asked whether a participant decided not to visit a physician according to the information found on the internet. The response to the question was "never," "once," "sometimes," or "often." We dichotomized the responses into "never" and "ever," where "ever" includes once, sometimes, and often.

The physician visit variable measures whether a participant visited a physician in the last year. It is known that people seek health information for a wide variety of purposes, including deciding whether to visit a physician, preparing for a physician appointment, and reassurance, second opinion, and expanding knowledge on the information received from health care providers after a physician visit $[15,16,18,48]$. In other words, a participant may seek health information before or after a physician visit. Even when a participant seeks health information before a physician visit, the health information the participant obtains may not necessarily be used for deciding whether to visit a physician.

The variable of the decision to visit a physician measures whether a participant decided to visit a physician because of the health information the participant read online. Similarly, the variable of the decision not to visit a physician solely measures whether a participant decided not to visit a physician because of the health information the participant read online. Therefore, a subset of actual physician visits can be associated with decisions to visit made after reading online health information. 
If a participant never decides to visit a physician according to health information read on the internet, it does not necessarily mean the participant used the information to decide not to visit a physician and vice versa. The participant may have sought the health information for other purposes, may not have found the information useful, or may not have understood the information well enough to base decisions on it.

\section{Study Sample}

Figure 1 shows the study sample selection workflow. Of the 21,083 participants in Troms $\varnothing 7$, we excluded 2886 participants who had missing responses for one or more of the variables, such as age, gender, education, household income, occupation, Web search engine use, video search engine use, social media use, health app use, diseases, self-reported health status, and physician visit. The final study sample consisted of 18,197 participants (9251 women and 8946 men).

Figure 1. The study sample selection workflow.

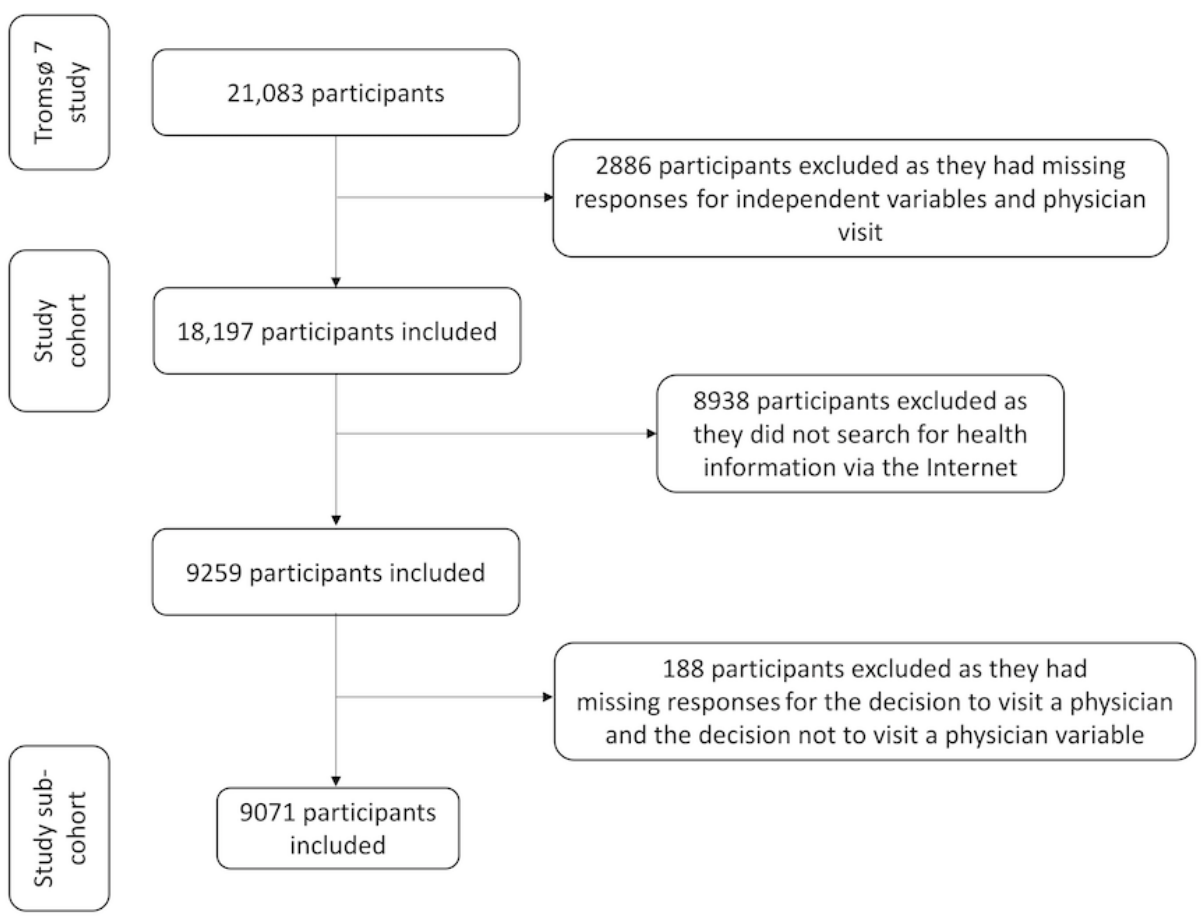

Of the 18,197 participants included in this study, 9259 participants sought health information via one or more eHealth tools. Of these 9259 participants, we subsequently excluded 188 participants with missing information regarding the variables of the decisions to visit and not to visit a physician. As a result, a subcohort that consisted of 9071 participants (5110 women and 3961 men) was created.

\section{Statistical Analysis}

Descriptive statistics were calculated to summarize the dependent and independent variables. Multivariable logistic regression models were fitted for the following three outcome variables of interest: (1) physician visit; (2) decision to visit a physician according to health information read on the internet; and (3) decision not to visit a physician according to health information read on the internet. The first model was fitted on the whole cohort dataset $(n=18,197)$, and the other two models were fitted on the subcohort dataset $(n=9071)$.

We used purposeful selection of independent variables for each of the logistic regression models as proposed by Hosmer et al [49]. First, we fitted the model with only one independent variable. Second, we fitted a multivariable model with all independent variables whose $P$ values were $<.25$ in the previous step. Third, we iteratively checked whether variables not significant (Wald test and .05 alpha value) in the multivariable model provided important adjustment to other variables that remained in the model. Important adjustment was measured by a change in coefficients by more than $20 \%$ between the multivariable models with and without the variable. Variables that provided important adjustment were added back into the multivariable model. Fourth, to ensure we did not miss any important variables, we added independent variables not added in the second step, one at a time to the multivariable model, using the Wald test to verify the effect of each additional variable at an alpha value of .05. Thereafter, we added all independent variables that were significant to the multivariable model. Fifth, we explored possible interactions of age, gender, and education with the use of eHealth tools. We also explored possible interactions between age and disease, age and self-reported health, age and household income, education and household income, education and disease, education and self-reported health, household income and disease, self-reported health and disease, and household income and self-reported health. We added the interactions, one at a time, to the multivariable model at the end of step four and tested significance using a likelihood ratio test and an alpha value of .1. Following separate analysis of each of the interaction terms, we added each significant interaction term to the model at the end of step four and removed interaction terms that were not 
significant with the Wald test and an alpha value of .05. Thereafter, we fitted the model excluding the nonsignificant interactions. Sixth, we checked the fitness of the model with regard to the data using the Hosmer-Lemeshow goodness-of-fit test.

We tested statistical significance at an alpha level of .05. All analyses were conducted using $\mathrm{R}$ statistical software (version 3.4.0; R Project for Statistical Computing, Vienna, Austria). All the ORs reported in the paper are adjusted ORs.

\section{Ethics}

Troms $\emptyset 7$ was approved by the North Norway Regional Committee for Medical and Health Research Ethics (REK Nord, reference 2014/940). All participants provided written informed consent for Troms $\varnothing 7$.

\section{Results}

\section{Participants' Characteristics}

Characteristics of the study participants are summarized in Table 1. Of the 18,197 study participants, 9251 (50.84\%) were women and $8948(49.16 \%)$ were men. The mean age of the overall study sample $(\mathrm{n}=18,197)$ was 56.38 years, with $51.10 \%$ (9298) of participants having a college education. About three-fourths of the participants $(73.22 \%, 13,323 / 18,197)$ had one or more diseases, 50.88\% $(9259 / 18,197)$ sought health information via one or more eHealth tools, and $80.38 \%(14,627 / 18,197)$ had a physician visit in the last year. 
Table 1. Characteristics of the study sample.

\begin{tabular}{|c|c|c|c|c|}
\hline \multirow[t]{2}{*}{ Variable } & \multicolumn{2}{|c|}{ Cohort $(n=18,197)$} & \multicolumn{2}{|c|}{ Subcohort $(n=9071)$} \\
\hline & Count & Percentage & Count & Percentage \\
\hline \multicolumn{5}{|l|}{ Gender } \\
\hline Female & 9251 & 50.84 & 5110 & 56.33 \\
\hline Male & 8946 & 49.16 & 3961 & 43.67 \\
\hline Age, years & $56.38^{\mathrm{a}}$ & $11.00^{\mathrm{b}}$ & $52.60^{\mathrm{a}}$ & $9.25^{\mathrm{b}}$ \\
\hline \multicolumn{5}{|l|}{ Education } \\
\hline Primary or secondary & 3831 & 21.05 & 970 & 10.69 \\
\hline Upper secondary & 5068 & 27.85 & 2280 & 25.13 \\
\hline Less than 4 years of college & 3650 & 20.06 & 2086 & 23.00 \\
\hline Four years or more of college & 5648 & 31.04 & 3735 & 41.18 \\
\hline \multicolumn{5}{|l|}{ Household income (US) ${ }^{c}$} \\
\hline$<39000$ US & 2132 & 11.72 & 568 & 6.26 \\
\hline $39000-61000$ US & 3725 & 20.47 & 1632 & 18.00 \\
\hline $61000-83000$ US & 3242 & 17.81 & 1519 & 16.74 \\
\hline $83000-111000$ US & 4396 & 24.16 & 2449 & 27.00 \\
\hline$>111000$ US & 4702 & 25.84 & 2903 & 32.00 \\
\hline \multicolumn{5}{|l|}{ Occupation } \\
\hline Full-time work & 11,145 & 61.25 & 6461 & 71.23 \\
\hline Part-time work & 1453 & 7.99 & 783 & 8.63 \\
\hline Unemployed & 122 & 0.67 & 70 & 0.77 \\
\hline Housekeeping & 99 & 0.54 & 29 & 0.32 \\
\hline Retired & 3720 & 20.44 & 912 & 10.05 \\
\hline Student/military service & 55 & 0.30 & 39 & 0.43 \\
\hline Disability and other family welfare benefits & 1603 & 8.81 & 777 & 8.57 \\
\hline \multicolumn{5}{|l|}{ Disease } \\
\hline Yes & 13,323 & 73.22 & 6688 & 73.73 \\
\hline No & 4874 & 26.78 & 2383 & 26.27 \\
\hline \multicolumn{5}{|l|}{ Self-reported health status } \\
\hline Very bad & 54 & 0.29 & 27 & 0.30 \\
\hline $\mathrm{Bad}$ & 909 & 4.99 & 508 & 5.60 \\
\hline Neither bad nor good & 4583 & 25.19 & 2082 & 22.95 \\
\hline Good & 9891 & 54.36 & 5003 & 55.15 \\
\hline Very good & 2760 & 15.17 & 1451 & 16.00 \\
\hline \multicolumn{5}{|l|}{ Physician visit } \\
\hline Yes & 14,627 & 80.38 & 7496 & 82.64 \\
\hline No & 3570 & 19.62 & 1575 & 17.36 \\
\hline \multicolumn{5}{|l|}{ Web search engine use } \\
\hline Ever & 8956 & 49.22 & 8773 & 96.71 \\
\hline Never & 9241 & 50.78 & 298 & 3.29 \\
\hline \multicolumn{5}{|l|}{ Video search engine use } \\
\hline Ever & 900 & 4.95 & 875 & 9.65 \\
\hline
\end{tabular}




\begin{tabular}{|c|c|c|c|c|}
\hline \multirow[t]{2}{*}{ Variable } & \multicolumn{2}{|c|}{ Cohort $(\mathrm{n}=18,197)$} & \multicolumn{2}{|c|}{ Subcohort $(\mathrm{n}=9071)$} \\
\hline & Count & Percentage & Count & Percentage \\
\hline Never & 17,297 & 95.05 & 8196 & 90.35 \\
\hline \multicolumn{5}{|c|}{ Social media use } \\
\hline Ever & 1259 & 6.92 & 1223 & 13.48 \\
\hline Never & 16,938 & 93.08 & 7848 & 86.52 \\
\hline \multicolumn{5}{|l|}{ App use } \\
\hline Ever & 2358 & 12.96 & 2299 & 25.34 \\
\hline Never & 15,839 & 87.04 & 6772 & 74.66 \\
\hline \multicolumn{5}{|c|}{ eHealth use $^{d}$} \\
\hline Ever & 9259 & 50.88 & 9071 & 100 \\
\hline Never & 8938 & 49.12 & 0 & 0 \\
\hline \multicolumn{5}{|c|}{ Decision to visit a physician } \\
\hline Ever & $-^{\mathrm{e}}$ & - & 2075 & 22.88 \\
\hline Never & - & - & 6996 & 77.12 \\
\hline \multicolumn{5}{|c|}{ Decision not to visit a physician } \\
\hline Ever & - & - & 2093 & 23.07 \\
\hline Never & - & - & 6978 & 76.93 \\
\hline
\end{tabular}

${ }^{\mathrm{a}}$ The value is mean age.

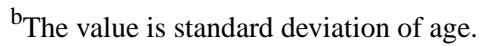

${ }^{\mathrm{c}}$ One US dollar is approximately 9 Norwegian $\mathrm{kr}$.

${ }^{d}$ It includes the use of one or more tools, such as Web search engines, health apps, video search engines, and social media.

${ }^{\mathrm{e}}$ Not applicable.

Among our subcohort of 9071 participants who sought health information using one or more eHealth tools, 2075 (22.88\%) decided to visit a physician and $2093(23.07 \%)$ decided not to visit a physician according to the information they found. Among these participants, 1047 (11.54\%) decided both to visit a physician and not to visit a physician in the last year. In other words, $34.40 \%$ (3121/9071) of the subcohort used the health information as a basis for one or more decisions.

\section{Actual Physician Visit (n=18,197)}

The independent variables selected in the multivariable logistic regression model for a physician visit were age, gender, education, household income, occupation, disease, self-reported health, Web search engine use, video search engine use, social media use, and health app use. The interactions between gender and health app use, age and disease, and age and Web search engine use were statistically significant in the multivariable model. The likelihood ratio test $\left(\chi_{3}^{2}=31.89, P<.001\right)$ of the models with and without the interaction terms indicated that the interactions had statistically significant contributions to the model. The Hosmer-Lemeshow goodness-of-fit test $\chi_{8}^{2}=12.57$, $P=.13)$ indicated that the model fitted with the data very well, which means the observed and predicted values had no statistically significant difference $(P=.13)$.

As shown in Table 2, the model revealed that a physician visit was predicted by Web search engine use, age, gender, education, household income, occupation, and self-reported health. Health app use, video search engine use, and social media use did not predict a physician visit. 
Table 2. Odds ratios and 95\% confidence intervals in the logistic regression analysis of the association between online health information seeking and a physician visit $(n=18,197)$.

\begin{tabular}{lll}
\hline Variable & OR $(95 \% \mathrm{CI})$ & $P$ value \\
\hline Age (per 10-year interval) & $1.27(1.17-1.37)$ & $<.001$
\end{tabular}

\section{Gender}

Female

Male

Education

Primary and secondary

Upper secondary

Less than 4 years of college

Four years or more of college

\section{Household income (US) ${ }^{\text {a }}$}

$$
\begin{aligned}
& <39000 \text { US } \\
& 39000-61000 \text { US } \\
& 61000-83000 \text { US } \\
& >83000 \text { US }
\end{aligned}
$$

\section{Occupation}

Full-time work

Part-time work

Unemployed

Housekeeping

Retired

Student/military service

Disability and other family welfare benefits

\section{Web search engine use}

$$
\text { Never }
$$

Ever

Video search engine use

$$
\text { Never }
$$

Ever

\section{Social media use}

Never

Ever

App use
Never
Ever

Disease
Never
Ever

\section{Self-reported health}

Very bad

Bad

Neither bad nor good
1.00

$0.60(0.55-0.66)$

$<.001$

1.00

$1.02(0.90-1.15) \quad .78$

$0.98(0.85-1.12) \quad .75$

$0.78(0.68-0.88)<.001$

1.00

$1.28(1.08-1.52) \quad .005$

$1.32(1.10-1.57) \quad .002$

$1.23(1.04-1.46) \quad .02$

1.00

$1.26(1.06-1.50) \quad .008$

$0.76(0.49-1.20) \quad .23$

$0.59(0.36-1.02) \quad .047$

$1.00(0.85-1.19) \quad .96$

$0.68(0.37-1.31) \quad .22$

$1.65(1.34-2.05) \quad<.001$

1.00

$3.69(2.33-5.83)<.001$

1.00

$0.95(0.77-1.17)$

1.00

$0.89(0.75-1.08)$

1.00

$1.00(0.84-1.20) \quad .98$

1.00

$1.22(0.79-1.88)$

1.00

$0.36(0.02-1.73) \quad .32$

$0.20(0.01-0.92)$
.11 


\begin{tabular}{lll}
\hline Variable & OR $(95 \% \mathrm{CI})$ & $P$ value \\
\hline \multicolumn{1}{c}{ Good } & $0.12(0.01-0.57)$ & .04 \\
$\quad$ Very good & $0.07(0.004-0.33)$ & .009 \\
Gender, male; app use, ever & $1.34(1.05-1.71)$ & .02 \\
Age; disease, ever & $1.16(1.07-1.25)$ & $<.001$ \\
Age; Web search engine use, ever & $0.86(0.79-0.93)$ & $<.001$ \\
\hline
\end{tabular}

${ }^{\mathrm{a}}$ One US dollar is approximately 9 Norwegian $\mathrm{kr}$.

The statistically significant interaction between Web search engine use and age indicated that the association between Web search engine use and physician visit was moderated by age. In other words, the OR for Web search engine use was not constant over different ages. Therefore, the meaningful ORs of Web search engine use at different ages needed to be derived from the coefficients of Web search engine use, age, and the interaction term (see [49] for an elaborate description on how the ORs are derived). In general, Web search engine use had lower odds of a physician visit as age increased. For example, at age 40 years, those who used Web search engines had 1.99 (95\% CI 1.94-2.02) times higher odds of a physician visit as compared with those who did not use Web search engines. However, at age 80 years, those who used Web search engines had 1.07 (95\% CI 1.03-1.12) times higher odds of a physician visit.

Men had lower odds of a physician visit as compared with women. High household income was positively associated with higher odds of a physician visit as compared with household income less than 350,000 Norwegian kroner.

Those with 4 or more years of college education had $22 \%(95 \%$ CI 0.68-0.88) lower odds of a physician visit as compared with those who had a primary or secondary education. However, no difference regarding a physician visit was found for the other education levels.
A physician visit was both positively and negatively predicted depending on the type of occupation. It was positively predicted by part-time work (OR 1.26, 95\% CI 1.06-1.50) and disability and other family welfare benefits (OR 1.65, 95\% CI 1.34-2.05) as compared with full-time work. Those who listed housekeeping as their occupation had $41 \%$ (95\% CI 0.36-1.02) lower odds of a physician visit.

\section{Decision to Visit a Physician ( $\mathbf{n = 9 0 7 1 )}$}

The independent variables selected in the multivariable logistic regression model for the decision to visit a physician were age, gender, education, occupation, self-reported health, Web search engine use, video search engine use, social media use, and health app use. The interaction between gender and social media use was statistically significant in the multivariable model. The likelihood ratio test $\left(\chi_{1}^{2}=4.96, P=.02\right)$ of the models with and without the interaction term indicated that the interaction had a statistically significant contribution to the model. The Hosmer-Lemeshow goodness-of-fit test $\left(\chi_{8}^{2}=5.2, P=.74\right)$ showed that the model's prediction of whether the participants decided to visit a physician according to the health information they read did not significantly differ $(P=.74)$ from the actual values reported by the participants.

As shown in Table 3, the model revealed that the decision to visit a physician was predicted by Web search engine use, health app use, video search engine use, social media use, age, gender, education, and occupation. 
Table 3. Odds ratios and 95\% confidence intervals in the logistic regression analysis of the association between online health information seeking and the decision to visit a physician $(\mathrm{n}=9071)$.

\begin{tabular}{|c|c|c|}
\hline Variable & OR $(95 \% \mathrm{CI})$ & $P$ value \\
\hline Age (per 10-year interval) & $0.73(0.68-0.79)$ & $<.001$ \\
\hline \multicolumn{3}{|l|}{ Gender } \\
\hline Female & 1.00 & \\
\hline Male & $0.87(0.78-0.98)$ & .02 \\
\hline \multicolumn{3}{|l|}{ Education } \\
\hline Primary and secondary & 1.00 & \\
\hline Upper secondary & $1.18(0.97-1.43)$ & .11 \\
\hline Less than 4 years of college & $1.25(1.03-1.53)$ & .03 \\
\hline Four years or more of college & $1.34(1.11-1.62)$ & .003 \\
\hline \multicolumn{3}{|l|}{ Occupation } \\
\hline Full-time work & 1.00 & \\
\hline Part-time work & $0.92(0.76-1.10)$ & .36 \\
\hline Unemployed & $0.83(0.45-1.45)$ & .54 \\
\hline Housekeeping & $0.95(0.35-2.26)$ & .92 \\
\hline Retired & $1.11(0.87-1.42)$ & .40 \\
\hline Student/military service & $0.86(0.40-1.73)$ & 69 \\
\hline Disability and other family welfare benefits & $1.39(1.14-1.68)$ & $<.001$ \\
\hline \multicolumn{3}{|l|}{ Web search engine use } \\
\hline Never & 1.00 & \\
\hline Ever & $2.95(2.03-4.46)$ & $<.001$ \\
\hline \multicolumn{3}{|l|}{ Video search engine use } \\
\hline Never & 1.00 & \\
\hline Ever & $1.43(1.21-1.70)$ & $<.001$ \\
\hline \multicolumn{3}{|l|}{ Social media use } \\
\hline Never & 1.00 & \\
\hline Ever & $1.43(1.20-1.69)$ & $<.001$ \\
\hline \multicolumn{3}{|l|}{ App use } \\
\hline Never & 1.00 & \\
\hline Ever & $1.26(1.13-1.42)$ & $<.001$ \\
\hline \multicolumn{3}{|l|}{ Self-reported health } \\
\hline Very bad & 1.00 & \\
\hline Bad & $1.43(0.58-4.02)$ & .46 \\
\hline Neither bad nor good & $1.45(0.60-4.04)$ & .44 \\
\hline Good & $1.27(0.53-3.53)$ & .62 \\
\hline Very good & $0.96(0.40-2.70)$ & .94 \\
\hline Gender, male; social media use, ever & $0.70(0.51-0.96)$ & .03 \\
\hline
\end{tabular}

Those who used Web search engines had 2.95 times higher odds of deciding to visit a physician as compared with those who did not use Web search engines (95\% CI 2.03-4.46). The association of the decision to visit a physician with Web search engine use was higher than the association with other eHealth tools. Those who used health apps had 1.26 times higher odds (95\% CI 1.13-1.42) and those who used video search engines had 1.43 times higher odds (95\% CI 1.21-1.70) of deciding to visit a physician.

The statistically significant interaction between social media use and gender indicated that the association between the decision to visit a physician and social media use was moderated by gender. In other words, the OR of social media use was not 
the same for male and female participants. Therefore, the ORs of social media use for male and female participants needed to be derived from the coefficients of social media use, gender, and the interaction term (see [49] for an elaborate description on how ORs are derived). Women who used social media had 1.42 times higher odds of deciding to visit a physician as compared with those who did not use social media (95\% CI 1.31-1.55), whereas among men, there was no difference between those who used social media and those who did not use social media.

Similarly, because of the interaction, the meaningful ORs for gender were different between a social media user and nonuser, and they needed to be derived from the coefficients of social media use, gender, and the interaction term. Men who used social media had 39\% (95\% CI 0.55-0.69) lower odds of deciding to visit a physician as compared with women who used social media, whereas men who did not use social media had $13 \%$ (95\% CI 0.86-0.88) lower odds as compared with women. A 10-year age increment was associated with $27 \%(95 \% \mathrm{CI}$ 0.68-0.79) lower odds of deciding to visit a physician according to the health information found on the internet.

Higher education positively predicted a physician visit. Participants with less than 4 years of college education had 1.25 (95\% CI 1.03-1.53) times higher odds of deciding to visit a physician as compared with those having a primary or secondary education, whereas participants with more than 4 years of college education had 1.34 (95\% CI 1.11-1.62) times higher odds. Those who received disability and other family welfare benefits had 1.39 (95\% CI 1.14-1.68) times higher odds of deciding to visit a physician as compared with full-time workers.

\section{Decision not to Visit a Physician $(\mathbf{n}=9071)$}

The independent variables selected in the multivariable logistic regression model for the decision not to visit a physician were age, gender, education, disease, Web search engine use, video search engine use, social media use, and health app use. No statistically significant interactions among the independent variables were found. The Hosmer-Lemeshow goodness-of-fit test $\left(\chi_{8}^{2}=6.74, P=.57\right)$ indicated that the model predicted the participants' decisions not to visit a physician very well.

As shown in Table 4, the model revealed that a physician visit was predicted by Web search engine use, health app use, video search engine use, social media use, age, gender, education, and disease.

Those who used Web search engines had 2.78 times higher odds of deciding not to visit a physician as compared with those who did not use Web search engines (95\% CI 1.92-4.18). The association of the decision not to visit a physician with Web search engine use was stronger than the association with other eHealth tools. Those who used health apps had 1.20 times higher odds (95\% CI 1.07-1.35), those who used video search engines had 1.27 times higher odds (95\% CI 1.07-1.51), and those who used social media had 1.28 times higher odds (95\% CI 1.10-1.49) of deciding not to visit a physician.

A 10-year age increment was associated with $22 \%$ (95\% CI $0.73-0.83$ ) lower odds of deciding not to visit a physician according to the health information found on the internet. Men had $33 \%$ lower odds of deciding not to visit a physician as compared with women (95\% CI 0.60-0.74). 
Table 4. Odds ratios and 95\% confidence intervals in the logistic regression analysis of the association between online health information seeking and the decision not to visit a physician $(\mathrm{n}=9071)$.

\begin{tabular}{|c|c|c|}
\hline Variable & OR $(95 \% \mathrm{CI})$ & $P$ value \\
\hline Age (per 10-year interval) & $0.78(0.73-0.83)$ & $<.001$ \\
\hline \multicolumn{3}{|l|}{ Gender } \\
\hline Female & 1.00 & \\
\hline Male & $0.67(0.60-0.74)$ & $<.001$ \\
\hline \multicolumn{3}{|l|}{ Education } \\
\hline Primary and secondary & 1.00 & \\
\hline Upper secondary & $1.09(0.90-1.33)$ & .37 \\
\hline Less than 4 years of college & $1.29(1.07-1.56)$ & .01 \\
\hline Four years or more of college & $1.20(0.99-1.44)$ & .06 \\
\hline \multicolumn{3}{|l|}{ Web search engine use } \\
\hline Never & 1.00 & \\
\hline Ever & $2.78(1.92-4.18)$ & $<.001$ \\
\hline \multicolumn{3}{|l|}{ Video search engine use } \\
\hline Never & 1.00 & \\
\hline Ever & $1.27(1.07-1.51)$ & .006 \\
\hline \multicolumn{3}{|l|}{ Social media use } \\
\hline Never & 1.00 & \\
\hline Ever & $1.28(1.10-1.49)$ & .001 \\
\hline \multicolumn{3}{|l|}{ App use } \\
\hline Never & 1.00 & \\
\hline Ever & $1.20(1.07-1.35)$ & .002 \\
\hline \multicolumn{3}{|l|}{ Disease } \\
\hline No & 1.00 & \\
\hline Yes & $1.18(1.05-1.32)$ & .006 \\
\hline
\end{tabular}

The decision not to visit a physician was positively predicted by education. Participants with less than 4 years of college education had 1.29 times higher odds of deciding not to visit a physician as compared with those having a primary or secondary education (95\% CI 1.07-1.56). Those who had one or more diseases in the past year had 1.18 times higher odds of deciding not to visit a physician as compared with those who did not have a disease (95\% CI 1.05-1.32).

\section{Discussion}

\section{Actual Physician Visit}

This study examined the association between a physician visit and health information seeking using eHealth tools (ie, Web search engines, video search engines, social media, and health apps). Our results indicated that a physician visit was positively predicted by health information seeking on Web search engines, which confirms the findings of some prior studies [37-40]. The use of Web search engines had a stronger association with a physician visit possibly because online health information seeking often starts with a Web search engine (ie, Google) $[17,40]$. However, the association was moderated by age, where the OR decreased as age increased. A physician visit was also positively predicted by higher household income, female gender, and older age, which is in line with the results found in other studies $[37,39,50]$. A physician visit was both positively and negatively predicted depending on the type of occupation.

A previous study has shown that the difference in physician visits between highly educated and less educated individuals is gradually decreasing in Norway [51]. A recent Norwegian study on patients with diabetes found no difference (95\% CI 0.44-5.59) regarding physician visits between highly educated and less educated individuals [44]. In general, our results were in line with existing findings on the lack of a difference in physician visits between highly educated and less educated individuals. However, we found that those who had 4 or more years of college education had lower odds of physician visits as compared with those who had primary and secondary education.

\section{Decision to Visit a Physician}

Of 9071 participants who sought health information online, $3121(34.40 \%)$ used the information they read to decide whether they needed to visit a physician. This is lower than the number reported in previous studies $[4,8,40]$. The difference can possibly be attributed to the fact that the participants included in this 
study were older than the participants in the other studies. In addition, differences in the health care systems (ie, publicly and privately funded) of the countries could cause varying access to health care services and, consequently, influence the reasons for seeking health information on the internet. It is possible that tax-funded health systems with small or no payment from patients are conducive to the use of traditional face-to-face consultations and to a lower use of eHealth as compared with health systems that are dependent on the financial situation of individuals. A previous study found that $88 \%$ of Norwegians prefer to see their GPs face-to-face [52]. Hence, the most common reasons Norwegians seek health information via the internet could be for purposes other than to decide whether to visit a physician.

Studies have shown that people seek health information on the internet for many reasons including deciding whether to visit a physician; preparing for a physician appointment; and reassurance, second opinion, and expanding knowledge on the information received after a physician visit $[15,16,18,48]$. Thus, the results of our model on a physician visit provided general information on how health information seeking is associated with a physician visit. On the other hand, the models for the decisions to visit a physician and not to visit a physician provided information on how health information seeking is specifically associated with each of these decisions.

Similar studies often use a single variable that measures whether participants decide to visit a physician according to the health information they read on the internet [40]. However, our study used two variables that measure participants' decisions to visit a physician and not to visit a physician. Our results showed that of 9071 participants who sought health information using eHealth tools, 1047 (11.54\%) decided both to visit a physician and not to visit a physician in the last year, a finding that would not have been captured by a single question.

Health information obtained from eHealth tools (ie, Web search engines, health apps, video search engines, and social media) positively predicted both the decision to visit a physician and the decision not to visit a physician. The positive associations of eHealth tools with both decisions would not have been revealed with a single model for both decisions. The association between social media use and the decision to visit a physician was moderated by gender. The association of Web search engine use with both decisions was stronger than the associations of other eHealth tools, which may be explained by the fact that online health information seeking often starts with a Web search engine (ie, Google) $[17,40]$.

Each eHealth tool showed a slightly stronger association with the decision to visit a physician than with the decision not to visit a physician. In other words, the odds of the decision to visit a physician according to the health information read online was greater than the odds of the decision not to visit a physician. Therefore, health information seeking via the internet overall slightly increased physician visits, supporting our findings on the positive association between health information seeking via Web search engines and actual physician visits.

Women had higher odds of making a decision according to the health information they read on the internet as compared with men. Receiving disability and other family welfare benefits was also associated with higher odds of deciding to visit a physician as compared with full-time workers. This difference might be attributed to the disease conditions that led to the welfare benefit.

Participants with one or more diseases had higher odds of deciding not to visit a physician according to the health information they read on the internet as compared with those who did not have a disease. Difficulty to interpret medical knowledge found on the internet is considered to increase physician visits [37]. Another study revealed that individuals diagnosed with a medical condition had a positive association with higher knowledge from the health information they read as compared with those who were not diagnosed with a disease [34], which is probably because they were better equipped to understand the health information. Consequently, these participants were able to make a decision according to what they read. These results highlight the potential of eHealth for managing chronic conditions.

Being older and less educated were associated with lower odds of deciding to visit a physician and deciding not to visit a physician according to the health information found on the internet. In other words, older and less educated individuals had lower odds of using the health information they found online to make a decision. These characteristics are known to negatively predict the use of eHealth in general $[17,40,45,53]$. These participants' lower odds of decision-making according to online health information might be attributed to a lack of necessary skills for navigating the internet, doubts regarding the quality or relevance of the health information available on the internet, or a view that physicians know best $[17,45]$. These differences signal a need to provide educational support to these population groups in particular.

Many individuals are likely to search the internet for health information to prepare for a physician appointment that has already been decided [8]. Deciding to visit a physician or not to visit a physician according to online health information is a choice individuals may make in connection with each search. There can be many rational reasons to see a physician after finding health information online. For instance, the information can substantiate worries that people may have concerning symptoms or illnesses. In some cases, people can find information suggesting that they are at increased risk of having or developing some illnesses, such as cardiovascular disorders and diabetes [54]. Some disorders can also be screened or diagnosed by the patient with the help of information found online, and this may necessitate further evaluation and treatment by health professionals [55].

However, we also recognize that the decision to visit or not to visit a physician after obtaining online health information is multifactorial. The findings of this study can be understood in light of the theory by Kuhltau [31,32] regarding information searching. The Information Search Process Model describes information seeking in six phases. It sees the process as complex and takes into consideration both cognitive and emotional factors, recognizing that information searchers can experience a range of feelings throughout the process, including optimism, satisfaction, confusion, and disappointment. 
In this study, overall, we found that online health information is associated with increased use of traditional health services (ie, visiting a physician). By drawing on the Information Search Process Model $[31,32]$, we understand that simply finding the relevant information may not be the endpoint of the process and that many online health information searchers will have feelings, such as confusion and frustration, even after finding the information they were looking for online. The decision to visit a physician following online health information searching may therefore also, in part, be based on emotional factors. People with health anxiety are more likely to visit a physician after finding health information online [33], supporting the idea that emotions also play an important role in the decision-making process.

\section{Implications}

We examined the importance of some central factors, such as demographic characteristics and health status, in the association between online health information searching and the decision to visit or not to visit a physician. However, drawing on the theory about health information searching [28-32], we emphasized the complexity of our topic, pointing out that the decision to visit a physician or not to visit a physician is based on a range of factors that we lack information about, including cognitive factors and emotional factors.

We believe that online health information has its place as part of a well-functioning health service and that much can be done to further improve the availability of quality online health information that will benefit patients and the general public [56,57]. Although we believe that this study has made a great contribution to the literature, many questions remain, and they should be addressed in future studies.

\section{Future Research}

There is a need for more studies related to this topic. For instance, studies that include psychological data about participants could provide important insights into the relevance of cognitive and emotional factors regarding how health information searchers react with respect to seeing a physician following health information searching [33]. Further studies are needed to examine what aspects of information sources contribute to deciding either to visit a physician or not to visit a physician. Issues, such as emotional content, understandability, usability, and readability, could be of importance [56]. Future studies could also address how health information searching influences other health-related behaviors, such as posting about health and illness on social media. Studies combining data on health information seeking via the internet and outcomes of physician visits are also needed to investigate whether access to eHealth might be conducive to unnecessary physician visits.

\section{Strengths and Limitations}

This study is based on cross-sectional data, with a large sample size and relatively good response rate. The invitation for participation was sent to all inhabitants of Troms $\emptyset$ aged 40 years or above by mail, which contributes to the representativeness of the study sample. Although prior studies have shown that the reproducibility and validity of self-reported findings from the Troms $\varnothing$ Study are quite high [58,59], there is still a possibility of recall bias, which may affect the validity of the results. High proportions of nonrespondents were men and older individuals, and people with one or more diseases and those who had physician visits were overrepresented among the participants [60].

Both the decision to search for health information on the internet and the decision to visit a physician or not to visit a physician are likely to be influenced by a range of different factors, including cognitive factors and emotional factors. Similarly, how people react to the use of eHealth services and traditional face-to-face services will be influenced by many different factors. We have taken some of the factors, such as demographic factors and health status, into account in this study regarding the relationship between online health information searching and physician visits, but there was a lack of information regarding many other variables that might be of interest. For instance, there was a lack of data on health anxiety that may moderate the relationship between health information seeking and the decision of whether to visit a physician.

The cross-sectional study design did not make it possible to establish causality, and the results might be affected by unmeasured confounding variables. With the current widespread use of the internet on smartphones and tablets, the difference between the use of search engines and apps may be blurry for some participants, which may affect the results.

\section{Conclusions}

In this study, we examined the association between health information seeking on the internet with a physician visit, making a decision to visit a physician, and making a decision not to visit a physician. We found that both the decision to visit a physician and the decision not to visit a physician were positively predicted by searching for health information online. However, searching for health information on the internet was associated with a resultant increase in physician visits. The implication of this finding is that for our participants, overall, online health information did not replace or reduce the need for traditional face-to-face health services. As such, online health information does not, at least in our study, stand out as a means for saving resources or resolving the demands on traditional resource-strained health services.

\section{Acknowledgments}

We thank the organizers, management, and technical staff of Troms $\varnothing 7$ for their valuable work in preparing and collecting the data. Above all, we thank the residents of Troms $\varnothing$. Their willingness to participate was fundamental to our research. This research was made possible by a grant from the Research Council of Norway to the Norwegian Centre for E-health Research, University Hospital of North Norway (Grant No 248150/O70) and UiT The Arctic University of Norway. The publication charge for this article was funded by a grant from the Publication Fund of UiT The Arctic University of Norway. 


\section{Conflicts of Interest}

None declared.

\section{References}

1. Statistics Norway. 2018. ICT usage in households URL: https://www.ssb.no/en/statbank/list/ikthus [accessed 2018-07-25]

2. Fox S. Pew Research Center. 2004. Older Americans and the Internet URL: https://www.pewresearch.org/internet/wp-content/ uploads/sites/9/media/Files/Reports/2004/PIP Seniors Online 2004.pdf.pdf [accessed 2018-07-25]

3. Santana S, Lausen B, Bujnowska-Fedak M, Chronaki CE, Prokosch H, Wynn R. Informed citizen and empowered citizen in health: results from an European survey. BMC Fam Pract 2011;12:20 [FREE Full text] [doi: 10.1186/1471-2296-12-20] [Medline: 21496309]

4. Fox S, Duggan M. Pew Research Center. 2013. Health Online 2013 URL: https://www.pewinternet.org/wp-content/uploads/ sites/9/media/Files/Reports/PIP HealthOnline.pdf [accessed 2020-02-06]

5. Cline R, Haynes K. Consumer health information seeking on the Internet: the state of the art. Health Educ Res 2001 Dec;16(6):671-692. [doi: 10.1093/her/16.6.671] [Medline: 11780707 ]

6. Eysenbach G. The impact of the Internet on cancer outcomes. CA Cancer J Clin 2003;53(6):356-371 [FREE Full text] [doi: 10.3322/canjclin.53.6.356] [Medline: 15224975]

7. Andreassen HK, Wangberg SC, Wynn R, Sørensen T, Hjortdahl P. [Health-related use of the Internet in the Norwegian population]. Tidsskr Nor Laegeforen 2006 Nov 16;126(22):2950-2952 [FREE Full text] [Medline: 17117194]

8. Andreassen HK, Bujnowska-Fedak MM, Chronaki CE, Dumitru RC, Pudule I, Santana S, et al. European citizens' use of E-health services: a study of seven countries. BMC Public Health 2007 Apr 10;7:53 [FREE Full text] [doi: 10.1186/1471-2458-7-53] [Medline: 17425798]

9. Wangberg S, Andreassen H, Kummervold P, Wynn R, Sørensen T. Use of the internet for health purposes: trends in Norway 2000-2010. Scand J Caring Sci 2009 Dec;23(4):691-696. [doi: 10.1111/j.1471-6712.2008.00662.x] [Medline: 19473317]

10. Rigby M, Koch S, Keeling D, Hill P, Alonso A. Europa. 2013. Developing a New Understanding of Enabling Health and Wellbeing in Europe Internet URL: https://ec.europa.eu/eip/ageing/library/ developing-new-understanding-enabling-health-and-wellbeing-europeharmonising-health-and en [accessed 2020-02-06]

11. Kummervold PE, Wynn R. Health information accessed on the internet: the development in 5 European countries. Int $\mathbf{J}$ Telemed Appl 2012;2012:297416-297413 [FREE Full text] [doi: 10.1155/2012/297416] [Medline: 23304133]

12. Atkinson NL, Saperstein SL, Pleis J. Using the internet for health-related activities: findings from a national probability sample. J Med Internet Res 2009;11(1):e4 [FREE Full text] [doi: 10.2196/jmir.1035] [Medline: 19275980]

13. Fox S. Pew Research Center. 2011. The Social Life of Health Information Internet, 2011 URL: https://www.pewresearch.org/ internet/wp-content/uploads/sites/9/media/Files/Reports/2011/PIP Social Life of Health Info.pdf [accessed 2020-02-06]

14. Jacobs W, Amuta AO, Jeon KC. Health information seeking in the digital age: An analysis of health information seeking behavior among US adults. Cogent Social Sciences 2017 Mar 13;3(1). [doi: 10.1080/23311886.2017.1302785]

15. Fox S, Lee R. Pew Research Center. 2000. The online health care revolution: How the Web helps Americans take better care of themselves URL: https://www.pewresearch.org/internet/wp-content/uploads/sites/9/media/Files/Reports/2000/ PIP Health Report.pdf.pdf [accessed 2015-03-20]

16. Powell J, Inglis N, Ronnie J, Large S. The characteristics and motivations of online health information seekers: cross-sectional survey and qualitative interview study. J Med Internet Res 2011 Feb;13(1):e20 [FREE Full text] [doi: 10.2196/jmir.1600] [Medline: 21345783]

17. Chu JT, Wang MP, Shen C, Viswanath K, Lam TH, Chan SS. How, When and Why People Seek Health Information Online: Qualitative Study in Hong Kong. Interact J Med Res 2017 Dec 12;6(2):e24 [FREE Full text] [doi: 10.2196/ijmr.7000] [Medline: 29233802]

18. Ziebland S, Chapple A, Dumelow C, Evans J, Prinjha S, Rozmovits L. How the internet affects patients' experience of cancer: a qualitative study. BMJ 2004 Mar 6;328(7439):564 [FREE Full text] [doi: 10.1136/bmj.328.7439.564] [Medline: $\underline{15001506]}$

19. Vambheim SM, Wangberg SC, Johnsen JK, Wynn R. Language use in an internet support group for smoking cessation: development of sense of community. Inform Health Soc Care 2013 Jan;38(1):67-78. [doi: 10.3109/17538157.2012.710685] [Medline: 22958060]

20. Powell JA, Darvell M, Gray JA. The doctor, the patient and the world-wide web: how the internet is changing healthcare. J R Soc Med 2003 Feb;96(2):74-76 [FREE Full text] [doi: 10.1177/014107680309600206] [Medline: 12562977]

21. Slev VN, Mistiaen P, Pasman HR, Verdonck-de Leeuw IM, van Uden-Kraan CF, Francke AL. Effects of eHealth for patients and informal caregivers confronted with cancer: A meta-review. Int J Med Inform 2016 Mar;87:54-67. [doi: 10.1016/j.ijmedinf.2015.12.013] [Medline: 26806712]

22. Robinson TN, Patrick K, Eng TR, Gustafson D. An evidence-based approach to interactive health communication: a challenge to medicine in the information age. Science Panel on Interactive Communication and Health. JAMA 1998 Oct 14;280(14):1264-1269. [doi: 10.1001/jama.280.14.1264] [Medline: 9786378] 
23. Eysenbach G, Köhler C. How do consumers search for and appraise health information on the world wide web? Qualitative study using focus groups, usability tests, and in-depth interviews. BMJ 2002 Mar 09;324(7337):573-577 [FREE Full text] [doi: 10.1136/bmj.324.7337.573] [Medline: 11884321]

24. Oyeyemi SO, Gabarron E, Wynn R. Ebola, Twitter, and misinformation: a dangerous combination? BMJ 2014 Oct 14;349:g6178. [doi: 10.1136/bmj.g6178] [Medline: 25315514]

25. Wynn R, Oyeyemi SO, Johnsen JK, Gabarron E. Tweets are not always supportive of patients with mental disorders. Int $\mathbf{J}$ Integr Care 2017 Jul 11;17(3):149. [doi: 10.5334/ijic.3261]

26. Gabarron E, Serrano JA, Wynn R, Lau AY. Tweet content related to sexually transmitted diseases: no joking matter. J Med Internet Res 2014 Oct 06;16(10):e228 [FREE Full text] [doi: 10.2196/jmir.3259] [Medline: 25289463]

27. Llanwarne N, Newbould J, Burt J, Campbell JL, Roland M. Wasting the doctor's time? A video-elicitation interview study with patients in primary care. Soc Sci Med 2017 Mar;176:113-122 [FREE Full text] [doi: 10.1016/j.socscimed.2017.01.025] [Medline: 28135690]

28. Lambert SD, Loiselle CG. Health information seeking behavior. Qual Health Res 2007 Oct;17(8):1006-1019. [doi: 10.1177/1049732307305199] [Medline: 17928475$]$

29. Miller SM. Monitoring and blunting: Validation of a questionnaire to assess styles of information seeking under threat. Journal of Personality and Social Psychology 1987;52(2):345-353. [doi: 10.1037/0022-3514.52.2.345]

30. Miller SM. Monitoring versus blunting styles of coping with cancer influence the information patients want and need about their disease. Implications for cancer screening and management. Cancer 1995 Jul 15;76(2):167-177. [doi: 10.1002/1097-0142(19950715)76:2<167::aid-cncr2820760203>3.0.co;2-k] [Medline: 8625088 ]

31. Kuhlthau C. Seeking Meaning: A Process Approach To Library And Information Services, 2nd Edition (Libraries Unlimited Guided Inquiry). Santa Barbara, CA: Libraries Unlimited; 2020.

32. Kuhlthau CC. The role of experience in the information search process of an early career information worker: Perceptions of uncertainty, complexity, construction, and sources. J Am Soc Inf Sci 1999;50(5):399-412. [doi:

10.1002/(sici)1097-4571(1999)50:5<399::aid-asi3>3.0.c0;2-1]

33. Baumgartner SE, Hartmann T. The role of health anxiety in online health information search. Cyberpsychol Behav Soc Netw 2011 Oct;14(10):613-618. [doi: 10.1089/cyber.2010.0425] [Medline: 21548797]

34. Budrionis A, Wynn R, Marco-Ruiz L, Yigzaw KY, Bergvik S, Oyeyemi S, et al. Impact of the Use of Electronic Health Tools on the Psychological and Emotional Well-Being of Electronic Health Service Users (The Seventh Troms $\varnothing$ Study Part 3): Population-Based Questionnaire Study. J Med Internet Res 2020 Mar 05;22(3):e13118 [FREE Full text] [doi: $10.2196 / 13118]$

35. Marco-Ruiz L, Bønes E, de la Asunción E, Gabarron E, Aviles-Solis JC, Lee E, et al. Combining multivariate statistics and the think-aloud protocol to assess Human-Computer Interaction barriers in symptom checkers. J Biomed Inform 2017 Oct;74:104-122 [FREE Full text] [doi: 10.1016/j.jbi.2017.09.002] [Medline: 28893671]

36. Lee K, Hoti K, Hughes JD, Emmerton L. Dr Google Is Here to Stay but Health Care Professionals Are Still Valued: An Analysis of Health Care Consumers' Internet Navigation Support Preferences. J Med Internet Res 2017 Jun 14;19(6):e210 [FREE Full text] [doi: 10.2196/jmir.7489] [Medline: 28615156]

37. Lee C. Does the internet displace health professionals? J Health Commun 2008;13(5):450-464. [doi: 10.1080/10810730802198839] [Medline: 18661387 ]

38. Eastin MS, Guinsler NM. Worried and wired: effects of health anxiety on information-seeking and health care utilization behaviors. Cyberpsychol Behav 2006 Aug;9(4):494-498. [doi: 10.1089/cpb.2006.9.494] [Medline: 16901253]

39. Hsieh RW, Chen L, Chen T, Liang J, Lin T, Chen Y, et al. The Association Between Internet Use and Ambulatory Care-Seeking Behaviors in Taiwan: A Cross-Sectional Study. J Med Internet Res 2016 Dec 07;18(12):e319 [FREE Full text] [doi: 10.2196/jmir.5498] [Medline: 27927606]

40. Ybarra ML, Suman M. Help seeking behavior and the Internet: a national survey. Int J Med Inform 2006 Jan;75(1):29-41. [doi: 10.1016/j.ijmedinf.2005.07.029] [Medline: 16129659]

41. Baker L, Wagner TH, Singer S, Bundorf MK. Use of the Internet and e-mail for health care information: results from a national survey. JAMA 2003 May 14;289(18):2400-2406. [doi: 10.1001/jama.289.18.2400] [Medline: 12746364]

42. Robinson TN. Community health behavior change through computer network health promotion: preliminary findings from Stanford Health-Net. Computer Methods and Programs in Biomedicine 1989 Oct;30(2-3):137-144. [doi: 10.1016/0169-2607(89)90065-5]

43. Spoelman WA, Bonten TN, de Waal MW, Drenthen T, Smeele IJ, Nielen MM, et al. Effect of an evidence-based website on healthcare usage: an interrupted time-series study. BMJ Open 2016 Nov 09;6(11):e013166 [FREE Full text] [doi: 10.1136/bmjopen-2016-013166] [Medline: 28186945]

44. Hansen AH, Broz J, Claudi T, Årsand E. Relations Between the Use of Electronic Health and the Use of General Practitioner and Somatic Specialist Visits in Patients With Type 1 Diabetes: Cross-Sectional Study. J Med Internet Res 2018 Nov 07;20(11):e11322 [FREE Full text] [doi: 10.2196/11322] [Medline: 30404766]

45. Wynn R, Oyeyemi S, Budrionis A, Marco-Ruiz L, Yigzaw K, Bellika JG. Electronic Health Use in a Representative Sample of 18,497 Respondents in Norway (The Seventh Troms $\varnothing$ Study - Part 1): Population-Based Questionnaire Study. JMIR Med Inform 2020 Mar 05;22(3):e13106 [FREE Full text] [doi: 10.2196/13106] 
46. Marco-Ruiz L, Wynn R, Oyeyemi S, Budrionis A, Yigzaw KY, Bellika JG. Impact of Illness on Electronic Health Use (The Seventh Troms $\varnothing$ Study - Part 2): Population-Based Questionnaire Study. J Med Internet Res 2020 Mar 05;22(3):e13116 [FREE Full text] [doi: 10.2196/13116]

47. Jacobsen BK, Eggen AE, Mathiesen EB, Wilsgaard T, Njølstad I. Cohort profile: the Tromso Study. Int J Epidemiol 2012 Aug;41(4):961-967 [FREE Full text] [doi: 10.1093/ije/dyr049] [Medline: 21422063]

48. Medlock S, Eslami S, Askari M, Arts DL, Sent D, de Rooij SE, et al. Health information-seeking behavior of seniors who use the Internet: a survey. J Med Internet Res 2015 Jan 08;17(1):e10 [FREE Full text] [doi: 10.2196/jmir.3749] [Medline: 25574815]

49. Hosmer D, Lemeshow S, Sturdivant R. Applied Logistic Regression, 3rd Edition. Hoboken, NJ: John Wiley \& Sons, Inc; 2013:978.

50. Nguyen HT, Nakamura K, Seino K, Vo VT. Association Between a Wider Availability of Health Information and Health Care Utilization in Vietnam: Cross-Sectional Study. J Med Internet Res 2017 Dec 18;19(12):e405 [FREE Full text] [doi: 10.2196/jmir.8328] [Medline: 29254911]

51. Vikum E, Bjørngaard JH, Westin S, Krokstad S. Socio-economic inequalities in Norwegian health care utilization over 3 decades: the HUNT Study. Eur J Public Health 2013 Dec;23(6):1003-1010. [doi: 10.1093/eurpub/ckt053] [Medline: 23729479]

52. Sørensen T, Andreassen H, Wangberg S. eHealth Research. 2013. E-helse i Norge 2013 URL: https://ehealthresearch.no/ files/documents/Rapporter/NST-rapport 2014-02 e-helse i Norge 2013.pdf [accessed 2018-07-25]

53. Ginossar T. Predictors of Online Cancer Prevention Information Seeking Among Patients and Caregivers Across the Digital Divide: A Cross-Sectional, Correlational Study. JMIR Cancer 2016 Mar 09;2(1):e2 [FREE Full text] [doi: 10.2196/cancer.5108] [Medline: 28410177]

54. Stiglic G, Pajnkihar M. Evaluation of Major Online Diabetes Risk Calculators and Computerized Predictive Models. PLoS One 2015;10(11):e0142827 [FREE Full text] [doi: 10.1371/journal.pone.0142827] [Medline: 26560153]

55. Vetter S, Rossegger A, Elbert T, Gerth J, Urbaniok F, Laubacher A, et al. Internet-based self-assessment after the Tsunami: lessons learned. BMC Public Health 2011 Jan 07;11:18 [FREE Full text] [doi: 10.1186/1471-2458-11-18] [Medline: 21214894]

56. Beaunoyer E, Arsenault M, Lomanowska AM, Guitton MJ. Understanding online health information: Evaluation, tools, and strategies. Patient Educ Couns 2017 Feb;100(2):183-189. [doi: 10.1016/j.pec.2016.08.028] [Medline: 27595436]

57. Tian C, Champlin S, Mackert M, Lazard A, Agrawal D. Readability, suitability, and health content assessment of web-based patient education materials on colorectal cancer screening. Gastrointest Endosc 2014 Aug;80(2):284-290. [doi: 10.1016/j.gie.2014.01.034] [Medline: 24674352]

58. Engstad T, Bonaa KH, Viitanen M. Validity of self-reported stroke: The Tromso Study. Stroke 2000 Jul;31(7):1602-1607. [doi: $10.1161 / 01 . s t r .31 .7 .1602]$ [Medline: 10884460$]$

59. Lundblad MW, Jacobsen BK. The reproducibility of self-reported age at menarche: The Troms $\varnothing$ Study. BMC Womens Health 2017 Aug 22;17(1):62 [FREE Full text] [doi: 10.1186/s12905-017-0420-0] [Medline: 28830397]

60. Statistics Norway. 2018. GPs and emergency primary health care URL: https://www.ssb.no/en/statbank/table/09535/ [accessed 2018-07-25]

\section{Abbreviations \\ eHealth: electronic health \\ GP: general practitioner \\ Tromsø 7: the seventh survey of the Tromsø Study}

Edited by G Eysenbach; submitted 12.12.18; peer-reviewed by MP Wang, T Ginossar, K Nakamura, D Sent, FC Wang; comments to author 08.04.19; revised version received 03.09.19; accepted 16.12.19; published 05.03.20

Please cite as:

Yigzaw KY, Wynn R, Marco-Ruiz L, Budrionis A, Oyeyemi SO, Fagerlund AJ, Bellika JG

The Association Between Health Information Seeking on the Internet and Physician Visits (The Seventh Troms $\emptyset$ Study - Part 4):

Population-Based Questionnaire Study

J Med Internet Res 2020;22(3):e13120

URL: https://www.jmir.org/2020/3/e13120

doi: $10.2196 / 13120$

PMID: 32134387 
CKassaye Yitbarek Yigzaw, Rolf Wynn, Luis Marco-Ruiz, Andrius Budrionis, Sunday Oluwafemi Oyeyemi, Asbjørn Johansen Fagerlund, Johan Gustav Bellika. Originally published in the Journal of Medical Internet Research (http://www.jmir.org), 05.03.2020. This is an open-access article distributed under the terms of the Creative Commons Attribution License (https://creativecommons.org/licenses/by/4.0/), which permits unrestricted use, distribution, and reproduction in any medium, provided the original work, first published in the Journal of Medical Internet Research, is properly cited. The complete bibliographic information, a link to the original publication on http://www.jmir.org/, as well as this copyright and license information must be included. 